\title{
DESALEITAMENTO DE BEZERROS HOLANDESES SUBMETIDOS A DIETAS DIFERENTES. I. DESEMPENHO PRODUTIVO.
}

\author{
C.S.LUCCI \\ Professor Adjunto \\ Faculdade de Medicina Veterinária e Zootecnia da USP \\ S.KUBOKI \\ Médico Veterinário \\ M.I. AOKI \\ Médico Veterinário \\ Y. BORTOLETTO \\ Médico Veterinário
}

J.R.B.C. ROSAS

Médico Veterinário

LUCCI, C.S. ; KOBOKI, S.; AOKI, M.1.; BORTOLFTTO, Y.; ROSAS, R.R.B.C. Desaleitamento de bezerros holandeses submetidos a dietas diferentes. 1. Desempenho produtivo. Rey. Fac. Med. vet. Zootec. Univ. S. Paulo, $17(1 / 2): 7-9.1980$.

RESUMO: Vinte e quatro bezerros machos Holandeses PC foram submetidos a quatro tratamentos os quais compreendiam, além de leite em quantidades restritas e mistura iniciadora até um máximo de 25 kg por bezerro e por dia, os seguintes alimentos: A) sem volumosos; B) feno de alfafa; C) feno de capim de Rhodes e D) silagem de milho. $O$ desaleitamento foi praticado ao fim de 7 semanas de idade, abrangendo o período experimental de 2 a á 12 a semanas de idade dentro de um delineamento em blocos inteiramente casualizados. Os ganhos de peso por bezerro e por dia foram: A) $0.356 \mathrm{~kg}$ : B) 0.519 $\mathrm{kg}$; C) $0,404 \mathrm{~kg}$ e D) $0,584 \mathrm{~kg}$. Os tratamentos B e D apresentaram ganhos significativamente maiores $(p \leqslant 0,01)$ que os demais. Concordando com isso, os bezerros em $\mathrm{D}$ ingeriram mais mistura iniciadora $(77,6 \mathrm{~kg})$ que aqueles no tratamento $(:(57,4 \mathrm{~kg})$; os bezerros em $\mathrm{D}$ e B $(73,1 \mathrm{~kg})$ comeram mais que aqueles em A $(52,1 \mathrm{~kg})$ - Uma das conclusões é que bezerros revelam um melhor desempenho quando em presença de forragens de alta palatabilidade.

UNITERMOS: Bezerros, desaleitamento * Nutricão *, ruminantes *

\section{INTRODUÇÃO}

O desaleitamento precoce de bezerros de racas leiteiras merece mais estudos em nosso meio, onde VEIGA ${ }^{*}$ estima que perto de 100.000 machos sejam sacrificados por ano, logo após o nascimento, para que o leite não seja desviado do comércio. Estes bezerros pertencem na maior parte a plantéis diferenciados, onde o leite tem colocação a preços mais elevados (tipo B). São animais com muita boa aptidão para ganhos de peso em sistemas de alimentação adequados, que poderiam além de suprir o mercado de carne, inclusive serem aproveitados em parte como melhoradores de plantéis menores, onde as condiçðes dificultam o emprego de inseminação artificial.

A importância de se empregar volumosos numa ração de desaleitamento precoce de bezerros é considerável, segundo ROY6. NOLLER, DICKSON e HILL ${ }^{5}$ associaram incidência de placas e erosões em mucosas de rumens de bezerros, com o fato de não receberem ou receberem pouca quantidade de volumosos em suas dietas. Esses AA sugeriram inclusive a colocação de feno na própria mistura iniciadora para forçar os animais a um consumo mínimo de forragem. Contrariamente, $\mathrm{HUBER}^{3}$ não julga indispensável o emprego de feno ou outro volumoso na ração de bezerros.

Sendo usados volumosos, a qualidade e tipo dos mesmos merecem estudos. CONRAD e HIBBS ${ }^{1}$ encontraram diferenças nos níveis de vitaminas do complexo B presentes nos rumens de bezerros que recebiam fenos de qualidades distintas. HIBBS, POUDEN e CONRAD ${ }^{2}$ concluiram que o feno a ser fornecido para bezerros deve ser da alta qualidade, sendo o feno de alfafa melhor em relação ao de gramíneas.

A finalidade do presente trabalho foi verificar se os vo. lumosos devem realmente ser incorporados numa dieta de desaleitamento precoce, comparar o feno de leguminosas com feno de gramíneas e pesquisar a possibilidade do emprego da silagem de milho como volumosos na dieta de bezerros, logo após o nascimento.

\section{MATERIAL E MÉTODOS}

Foram utilizados 24 bezerros machos, adquiridos de plantéis leiteiros, em um delineamento em blocos inteiramente casualizados, compondo-se os blocos conforme a ordem de nascimento, e sorteando-se os bezerros para um dos seguintes quatro tratamentos: A) sem volumosos; B) com feno de alfafa; C) com feno de capim de Rhodes (Chlorys gayana) e D) com silagem de milho. Os volumosos foram formecidos à vontade, sendo os fenos grosseiramente picados em pedaços de aproximadamente $2 \mathrm{~cm}$. Em todos os tratamentos forneceu-se leite $(168 \mathrm{~kg})$ até um máximo de $4,0 \mathrm{~kg}$ por dia, e mais uma mistura iniciadora, até um máximo de $2,5 \mathrm{~kg}$ por bezerro e por dia.

Os bezerros passavam a receber os alimentos sólidos a partir do quinto dia de idade, permanecendo em baias individuais. Tomou-se especial cuidado para que nas fazendas de origem, cada animal recebesse 6 refeiçōes de colostro $(10 \mathrm{~kg})$. As ofertas e sobras de cada alimento foram registradas diariamente e pesos vivos e alturas nas cernelhas, tomadas semanalmente.

$O$ período experimental desenvolveu-se da 2 à à 12 a semanas de idade fazendo-se o desaleitamento ao fim de 7 semanas. Amostragens dos alimentos ofertados foram colhidas no início, metade e fim do trabalho, desenvolvido de julho a novembro de 1.977 , em instalaçōes do CIZIP, Pirassununga, S. Paulo. Dois bezerros morreram durante o

\footnotetext{
- Veiga, J.S.M. Informação pessoal, 1976.
} 
período experimental, um com 21 e outro com 40 dias de idade, aparentemente sem relação com o tratamento que recebiam (tratamento D).

A mistura iniciadora possuia $25 \%$ de farelo de soja, $15 \%$ de farelinho de trigo, $54 \%$ de milho, $5 \%$ de leite em pó e $1 \%$ de sal + farinha de ossos, sendo preparada duas vezes durante a experimentação. Os fenos de alfafa e de Rhodes foram adquiridos no comércio, eram de boa qualidade, verdes e folhosos, isentos de materiais estranhos. Os fardos, ao serem abertos, mostraram bom aspecto e odor. A silagem de milho utilizada era a mesma preparada para o plantel leiteiro, de muito boa qualidade. Leite foi fornecido em baldes abertos, em duas refeições diárias até os 28 dias de idade e depois, apenas pela manhã, à mesma temperatura de 35 graus Celsius. Ãgua ficava à disposição dos bezerros, exceto nas meias horas seguintes às mamadas.

\section{RESULTADOS E DISCUSSĀO}

Os desempenhos em ganhos de peso e alturas são fornecidos na Tabela 1 , sendo as médias colocadas em quadrados mínimcs, em virtude da perda de duas das parcelas experimentais.

Tabela 1. (+) Ganhos de peso, em quilogramos; altura finais e ganhos em alturas, em centímetros; coeficientes de variação, em porcentagens.

$\begin{array}{cccc}\text { Tratamentos } & \begin{array}{c}\text { Ganhos diários } \\ \text { de peso }(\mathbf{k g})\end{array} & \begin{array}{c}\text { Alturas } \\ \text { finais }(\mathrm{cm})\end{array} & \begin{array}{c}\text { Ganhos em } \\ \text { Alturas }(\mathrm{cm})\end{array} \\ \text { A } & 0.356^{\mathrm{b}} & 79,66 & 7,16 \\ \text { B } & 0,519^{\mathrm{a}} & 84,25 & 9,08 \\ \text { C } & 0.404 \mathrm{~b} & 80.66 & 7.08 \\ \text { D } & 0.584^{\mathrm{a}} & 83,77 & 10,52 \\ \text { C.V. } & 13,86 \% & 4,86 \% & 36,03 \%\end{array}$

(+) Valores assinalados com letras desiguais diferem estatisticamente $(\mathrm{p} \leqslant 0.01)$.

Os tratamentos B e D, com feno de alfafa e com silagem de milho, apresentaram ganhos significativamente maiores que o $\mathrm{A}$ e o $\mathrm{C}$, respectivamente sem volumosos e com feno de gramíneas. Embora as alturas finais e ganhos em alturas não mostrassem diferenças estatísticamente significativas, houve a tendência para melhores desempenhos ocorrerem nos tratamentos B e D.

A velocidade de crescimento procurada foi a de cèrca de metade do potencial máximo, ou seja $0.875 \%$ do peso prévio até as 12 semanas de idade, conforme estabelecido por $\mathrm{ROY}^{6}$. No presente estudo, as curvas de crescimento dos bezerros foram colocadas em base logarítima, encontrando-se através de regressão linear as seguintes velocidades diárias de ganho, como porcentagens dos pesos prèviamente alcancados: A) $0.819 \%$; B) $1.069 \%$, C) $0.865 \%$ e D) $1.011 \%$. Nota-se assim que as velocidades de ganho nos tratamentos $B$ e $D$ excederam as expectativas, ao passo que principalmente no tratamento A, seria desejável um valor ligeiramente mais elevado. Assim, embora em nenhum caso fosse registrado ganho excessivamente reduzido e o aspecto dos bezerros fosse sempre satisfatório, os animais nos tratamentos $\mathrm{B}$ e D se destacaram como superiores. Os ganhos de peso mostraram-se ainda próximos aos obtidos anteriormente, com ração e manejo semelhantes ( $\mathrm{LUCCI}^{4}$ ).

O consumo de alimentos é apresentado na Tabela 2, em médias por bezerros e por períodos, para os diversos tratamentos.

Tabela 2. (+) Consumos de mistura iniciadora e de volumosos, em quilogramos. Dados em base de matéria seca, por períodos de 2 a 7,8 a $12 \mathrm{e}$ 2 a 12 semanas.

\begin{tabular}{lccccc} 
Alimentos & Periodos & \multicolumn{5}{c}{ Tratamentos } \\
& & A & B & C & D \\
Mistura & 2 a 7 & 16.57 & 26.41 & 17.05 & 25.71 \\
iniciadora & 8 a 12 & $35,54^{\mathrm{b}}$ & 46.75 & 40,34 & $53,10^{\mathrm{a}}$ \\
& $2 \mathrm{a} 12$ & $52,12^{\mathrm{c}}$ & $73,16^{\mathrm{ab}}$ & $57.40^{\mathrm{bc}}$ & $77.66^{\mathrm{a}}$ \\
Volumosos & $2 \mathrm{a} 7$ & & 3,44 & 2,15 & 2,11 \\
& $8 \mathrm{a} 12$ & & $5.38 \mathrm{a}$ & $2,14^{\mathrm{b}}$ & $6,96 \mathrm{a}$ \\
& $2 \mathrm{a} 12$ & & $8,84^{\mathrm{a}}$ & $4,29 \mathrm{~b}$ & $9.31 \mathrm{a}$ \\
Sólidos & $2 \mathrm{a} 7$ & 16,57 & 29,86 & 19,20 & 27.92 \\
& $8 \mathrm{a} 12$ & $35.54^{\mathrm{b}}$ & 52,13 & 42,49 & $60,07 \mathrm{a}$ \\
& $2 \mathrm{a} 12$ & $52,12^{\mathrm{b}}$ & $81,99^{\mathrm{a}}$ & $61,70^{\mathrm{b}}$ & $86,97^{\mathrm{a}}$
\end{tabular}

(+) Valores assinalados com letras desiguais, na mesma linha, diferem estatísticamente $(\mathrm{p} \leqslant 0.01)$

No consumo de misturas iniciais, o tratamento D superou o $\mathrm{C}$ e o $\mathrm{A}$, e o $\mathrm{B}$ superou o $\mathrm{A}$, em concordância com a situação de ganhos de pêso. Quanto aos volumosos, o feno de alfafa (B) e a silagem de milho (D) superaram nítidamente o feno de Rhodes (C). Isso vem de encontro ao conceito de que os fenos de gram ineas são preteridos em relação a fenos de leguminosas, mesmo quando o de gramíneas apresenta bom aspecto, como no caso presente. Para os alimentos volumosos, houve interrelação significativa entre tratamentos e períodos. Na Tabela 2, isolando-se os períodos de aleitamento ( 2 a 7 semanas) e pós-aleitamento ( 8 a 12 semanas) nota-se que o consumo de feno de alfafa foi 1.5 vezes maior no período pós aleitamento que no de aleitamento, o consumo de silagem foi 3.2 vezes maior enquanto que o de feno de Rhodes foi idêntico em ambos os períodos. Isso permite indicar o uso de silagem só após a 8 ạ semana de idade sendo o feno de alfafa a indicação ideal para bezerros mais novos conforme já fora afirmado por HIBBS, POUNDEN e CONRAD ${ }^{2}$. Outro fator importante é que a silagem, neste estudo, era de excelente qualidade, sem porções mofadas e com fermentação láctica homogenea em toda a massa. Na prática, uma silagem sem partes estragadas ou suspeitas, nem sempre é possível de se obter.

$\mathrm{O}$ consumo total de matéria seca proveniente de alimentos sólidos mostrou superioridade para os tratamentos $\mathrm{B}$ e $\mathrm{D}$, relativamente ao $\mathrm{C}$ e $\mathrm{A}$.

As correlações entre matéria seca ingerida como alimento concentrado versus matéria seca ingerida como alimento volumoso, para os tratamentos B,C e D, mostraram resultados positivos e significativos a $1 \%$ de probabilidade para $\mathrm{B}(\mathrm{r}=0,74914), \mathrm{C}(\mathrm{r}=0,59556)$ e $\mathrm{D}(\mathrm{r}=0,84121)$

A Tabela 3 mostra os resultados das análises bromato. logicas efetuadas nos alimentos, em porcentagens na matéria seca. 
Tabela 3. Resultados bromatológicos, em porcentagens na matéria seca, para os diversos alimentos. $\left({ }^{*}\right)$

$\begin{array}{cccrc}\begin{array}{c}\text { Resultados } \\ \text { em: }\end{array} & \begin{array}{c}\text { Feno de } \\ \text { alfafa }\end{array} & \begin{array}{c}\text { Feno de } \\ \text { Rhodes }\end{array} & \begin{array}{c}\text { Silagem } \\ \text { de milho }\end{array} & \begin{array}{c}\text { Mistura } \\ \text { iniciadora }\end{array} \\ \text { M.S. } & 87,86 & 89,54 & 32,68 & 88,26 \\ \text { P.B. } & 14,66 & 6,49 & 5,96 & 21,53 \\ \text { F.B. } & - & - & - & 5,52 \\ \text { E.E. } & 2,35 & 2,04 & 4,12 & 4,97 \\ \text { M.M. } & 7,74 & 6,60 & 4,12 & 9,86\end{array}$

\section{CONCLUSÕES}

Para as condições do presente trabalho foi possivel obter-se as seguintes conclusōes:

1. Os sistemas de desaleitamento com quantidades restritas de leite e misturas iniciadoras, devem incluir um volumoso de boa qualidade na ração.

2. O feno de alfafa mostrou-se o melhor dos volumosos aqui empregados, influindo de maneira positiva no consumo e consequente desempenho dos bezerros, em qualquer período de idade.

3. Os bezerros recebendo silagem de milho apresentaram resultados de ganhos de peso tão bons quanto os com feno de alfafa, mas o consumo inferior durante o período de aleitamento limita a recomendação da silagem para idades superiores a 8 semanas tomados os cuidados devidos.

4. A ingestão de maiores quantidades de volumosos não diminue a ingestão de concentrados ou vice-versa, pois ambas as ingestões estão correlacionadas de maneira positiva.

LUCCI C S ; KUBOKI S ; AOKI M I ; BORTOLETTO, Y.; ROSAS, R.R.B.C. Weaning of Holtein male calves with different diets. I. Feeding an growing performance. Rev. Fac. Med. vet. Zootec. Univ. S. Paulo, 17(1/2): 7-9, 1980.

SUMMARY: Twenty-four Holstein mael calves were used in a randonmized block design evaluating 4 treatments; A) without roughages; B) with alfalfa hay; C) with Rhodes grass hay and D) with corn silage. All the treatments had milk up to 7 weeks old and calf starter up to $2.5 \mathrm{~kg}$ per calf per day. The experimental period was from 2 to 12 weeks old. Average daily gains were: A: $0.356 \mathrm{~kg} ; \mathrm{B}: 0.519 \mathrm{~kg}$; C) $0.404 \mathrm{~kg}$ anda D: $0.548 \mathrm{~kg}$. Treatments $B$ and D presented significantly higher weight gains than $C$ and $A(p \leqslant 0.01)$ Calves on $D$ ingested more calf starter $(77.6 \mathrm{~kg})$ than calves on $C(57.4 \mathrm{~kg})$; the $B(73.1 \mathrm{~kg})$ and $D$ calves ingested more calf starter than ones on $A$ $(52.1 \mathrm{~kg})$. The conclusion is that calves had higher performances with good palatability roughages, and among the forrages alfalfa hay presented better results considering all periodos of life.

UNITERMS: Calves, weaning systems ${ }^{*}$; Nutrition, ruminant ${ }^{*}$,

\section{REFERÊNCIAS BIBLIOGRÁFICAS}

1 - CONRAD, H.R. \& HIBBS, J. W. A high roughage systems for raising calves based on early rumen development. Synthesis of thiamine and riboflavine in the rumen as influenced by the radio of hay to grain fed and initiation of dry feed consumption. J. Dairy Sci., 37(5): 512-22,1954.

2 - HIBBS, J.W.; POUNDEN, W.D. \& CONRAD, H.R. A high roughage system for raising calves based on early development of rumen function. I. Effect of variation in the ration on growth, feed consumption and utilization. J. Dairy Sci., 36(7): 717-27, 1953.

3 - HUBER, J.T. Desenvolvimento do aparelho digestivo. Simpósio de Nutrição de Ruminantes, Piracicaba, S.P., 1977.

4 - LUCCI, C.S. Desaleitamento precoce de bezerros. I. Níveis de energia e proteina nas rações iniciais. Rev. Fac. Med. vet. Zootec. Univ. S. Paulo, 13 (2) 317-25, 1976.

5 - NOLLER, C.H.; DICKSON, I. A.; HILL, D. L. Value of hay and rumen inoculation in an early weaning system for dairy calves. J. Dairy Sci..45(2): 197$201,1962$.

6 - ROY, J.H.B. The calves. London, Farmer e Stockbreeder, 1970 . v. 1.

Recebido para publicação em: 14.08 .1979 Aprovado para publicação em: 20.10.1980 